\title{
Feasible Management of Non-degradable Agricultural Mulching Film Wastes into Functional Flame-retarded Materials
}

\author{
Wenfan Yu, ${ }^{\text {a,b }}$ Xiangsheng Han, ${ }^{\text {a,b }}$ Hongzhen Cai, ${ }^{\text {a,b }}$ Wenyu $\mathrm{Lu},{ }^{\mathrm{a}, \mathrm{b}}$ Hang $\mathrm{Xu},{ }^{\mathrm{a}, \mathrm{b}}$ and \\ Weiming $\mathrm{Yi}^{\mathrm{a}, \mathrm{b}, *}$
}

\begin{abstract}
A feasible procedure was proposed to convert agriculture mulching film wastes into functional flame-retarded cotton stalk particles-polyethylenesandy soil composites (CS-PE-SS ) by simple compounding and injection molding. Due to the uniform dispersion of solid particles in polymer matrix and the promising interfacial combination and the potential interacting forces between cotton stalk and sandy soil particles, the resultant composites showed promising mechanical strength (a flexural strength of approximately $29.0 \mathrm{MPa}$, a tensile strength of approximately $15.8 \mathrm{MPa}$, and an impact strength of approximately $3.17 \mathrm{~kJ} / \mathrm{m}^{2}$ ) and improved thermal stabilities. The addition of sandy soil particles endowed materials with favorable flame-retarded properties, which can be resistant to fire ignition and flame out within $55 \mathrm{~s}$. Moreover, the actual agriculture wastes containing mulching film residues, cotton stalk, and soil from different areas of China were also successfully transformed into functional composites, which exhibited promising mechanical, thermal, and flameretarding properties. This study provided a simple, green, and low-cost strategy to convert agriculture mulching film wastes into functional materials, which can be recommended as a viable option to solve the problem of agriculture mulching film wastes.
\end{abstract}

Keywords: Agriculture waste; Sandy soil; Recyclability; Flame retardant; Materials

Contact information: a: School of Agricultural Engineering and Food Science, Shandong University of Technology, Zibo, 255000, China; b: Shandong Research Center of Engineering and Technology for Clean Energy, Zibo, 255000, China; *Corresponding author: yiweiming@sdut.edu.cn

\section{INTRODUCTION}

Plastic mulching film, one of the most commonly used materials in agricultural production, can conserve soil moisture and increase soil temperature in areas where irrigation is not available and the spring temperature is low; other benefits include higher crop yield and better crop quality (Gu et al. 2017; Lee et al. 2019; Chen et al. 2020; Hu et al. 2020). Typically, the major component of mulching film is low density and linear lowdensity polyethylene (Briassoulis and Schettini 2003; Kasirajan and Ngouajio 2012). This material is difficult to biodegrade due to its unique molecular structure and crystallinity, resulting in a great environmental burden ( $\mathrm{Ng}$ et al. 2018). Because of the incomplete recovery after the crop season, waste mulching film debris accumulates in soil, which negatively affects the soil quality, entangles with crop roots, and inhibits the absorption of water and nutrients, thus decreasing the crop yields and limiting the sustainable development of agriculture (Liu et al. 2018; Qi et al. 2018; de Souza Machado et al. 2019). Moreover, such plastic residues remaining in agricultural soil can enter the ecosystem, and the microplastics may be migrated by soil organisms as carriers for other soil pollutants, or 
become dust in the air, threatening the environment (Steinmetz et al. 2016; He et al. 2018). Thus, how to deal with mulching film waste in effective, green, and low-cost ways is an urgent problem needed to be solved in both agricultural production and environmental protection.

Many attempts have been made to deal with the agricultural mulching film wastes, such as the development and utilization of photodegradable or biodegradable materials, repeated use of plastics, weight reduction of mulching film, recycling, and incineration (Liu et al. 2014). Cyclic utilization and weight reduction of mulching film seems to be the simple way to deal with waste plastic residues. However, this strategy can only temporarily alleviate the aggravation of the problem, and collecting plastic in farmland will take a lot of time and labor. Incineration is the direct burning of agricultural residues in the field, which is another simple and direct method of waste treatment. Unfortunately, this option inevitably releases some air-borne particulates, greenhouse gas, and poses other serious consequences for the environment (Nkwachukwu et al. 2013; Vox et al. 2016). Biodegradable materials, such as mulching film, can be decomposed into small molecules after harvest season, becoming a promising strategy to reduce the pollution of the soil by plastic fragments. However, when biodegradable plastics are used in the actual environment, they often face the restriction of many environmental factors (e.g., temperature, $\mathrm{pH}$, or moisture) and enzymatic factors (e.g., enzyme preference for plastic polymer), making the degradation of biodegradable plastics complicated and unpredictable (Lambert and Wagner 2017; Sanchez-Hernandez et al. 2020). Mulching film can also be turned into fuel for power plants. Although this option can protect the environment and save energy, the large amount of pollutants carried on the mulching film and the cost pressure brought by the recovery make it difficult to effectively implement the mulching film collection (Hemphill 1993).

Recently, wood-plastic composites are emerging as favorable options to recycle agriculture wastes. The concept of wood-plastic composites is straightforward: fine powder of wood, or woody biomass from agricultural residues, is blended with polymers, such as polyethylene or polypropylene, via extrusion, injection, or compression moulding to form simple sections, such as planks, or more complex profiles (Chan et al. 2017; Mohanty et al. 2018). Wood-plastic composites have many advanced properties, such as low moisture absorption, low density, resistance to biological attack, good dimensional stability, and a combination of high specific stiffness and strength (Sommerhuber et al. 2015). As a consequence, they are widely used by owners in different fields, such as different outdoor and indoor applications, like fencing, decking, railing, docks, landscaping timbers, windows, doors, and various parts of automobiles (Borah and Kim 2016). For the improvement of the material properties of wood-plastic composites, inorganic fillers, including red mud (Liu et al. 2016), mineral fillers (Guzel et al. 2016), montmorillonite (Zhu et al. 2019), nano-zinc oxide (Abdel-Rahman et al. 2020), and nano-silica (Hao et al. 2018; Ma et al. 2019), are added into the materials. For example, Vigneshwaran et al. (2019) used red mud and sisal fiber as fillers to reinforce unsaturated polyester resin, and the addition of red mud improved mechanical and waterproof properties of composites. Matykiewicz et al. (2019) added basalt powder to epoxy resin to enhance the thermomechanical properties, stiffness, and hardness of the composites. Liu et al. (2016) modified wood flour (WF) with sodium-montmorillonite (Na-MMT) and then compounded with polylactic acid (PLA). The physical properties, most of the mechanical properties, and thermal properties of the obtained composites were improved. Sandy soil is also an inorganic matter, and after crops were harvested, it will inevitably adhere to the 
mulching film wastes and agricultural residues. Thus, an opportunity was provided to convert mulching film wastes and inorganic soil into functional wood-plastic composites with favorable strength and potential flame retarded properties, which were suitable as building materials, interior decoration, landscaping wood, doors and tables, etc.

Herein, cotton stalk particles-polyethylene-sandy soil composites (CS-PE-SS ${ }_{\mathrm{x}}$ ) were fabricated by simple high-speed mixing, mini-twin-screw extrusion, and micro injection molding procedures. Unlike traditional preparation of wood-plastic composites that use maleic acid polyethylene (MAPE) as compatibilizer to optimize the interface combination between hydrophobic polyethylene matrix and hydrophilic biomass (Tong et al. 2014; Mu et al. 2018), the addition of sandy soil (without MAPE) offered a procedure with easy preparation capability and relatively low cost. Due to the uniform dispersion of solid particles in the polymer matrix, the promising interface combination and the potential interacting forces between biomass and the oxygen groups on the surface of sandy soil, the resultant composites exhibited improved mechanical strength (flexural strength of approximately $29.0 \mathrm{MPa}$, tensile strength of approximately $15.8 \mathrm{MPa}$, and an impact strength of approximately $3.17 \mathrm{~kJ} / \mathrm{m}^{2}$ ). Due to the intrinsic flame-retarded properties of inorganic sandy soil and their uniform distribution in polymer matrix, the composites also showed a higher limiting oxygen index (LOI) value of $24.1 \%$ compared with $20.8 \%$ of composites without sandy soil. The composites were barely ignited by flame envelope for $10 \mathrm{~s}$ and exhibited flame out within $55 \mathrm{~s}$. Furthermore, composites were also obtained by actual agriculture mulching film wastes from different areas of China (e.g., Shandong, Jiangsu, and Xinjiang). This work may pave a simple, green, and low-cost way for the feasible management of mulching film wastes into functional flame-retarded materials.

\section{EXPERIMENTAL}

\section{Materials}

High-density polyethylene (HDPE, 9001) with a melt flow index of $0.05 \mathrm{~g} / 10 \mathrm{~min}$ was purchased from Taiwan Plastic Co., Ltd. (Taiwan, China). Linear low-density polyethylene (LLDPE, PF0218) with a melt flow index of $2 \mathrm{~g} / 10$ min was bought from Xingyu Plastic Chemical Co., Ltd. (Suzhou, China). The cotton stalk (CS) was from Liaocheng, China, and crushed as particles with sizes between $80-(178 \mu \mathrm{m})$ and 100-mesh $(125 \mu \mathrm{m})$. The sandy soil (SS) with a particle size less than 140-mesh (104 $\mu \mathrm{m})$ was obtained from Liaocheng, China.

\section{Preparation of CS-PE-SS Composites $_{x}$}

The preparation procedure of CS-PE-SS $\mathrm{x}_{\mathrm{x}}$ composites is illustrated in Fig. 1. Cotton stalk powder, sandy soil, and polyethylene (the main constituent in mulching film) were chosen as main components to imitate the natural agriculture wastes (Fig. 1A). As a biofiber, cotton stalk mainly consists of cellulose, hemicellulose, and lignin, and the fibrous morphology and the presence of polar groups $(-\mathrm{OH},-\mathrm{COOH}$, and other polar groups) made them promising in the fabrication of functional composites (Zheng et al. 2015; Yang et al. 2019). Moreover, sandy soil mainly consists of silicon dioxide, which was characterized of the oxygen-containing group (-OH and -O-), may exist some interacting forces with biofiber and facilitate the materials manufacture (Wang et al. 2020).

Typically, sandy soil and cotton stalk were dried at $100{ }^{\circ} \mathrm{C}$ for $24 \mathrm{~h}$. Then, specific ratios (Table 1) of dried cotton stalk powder, sandy soil, HDPE, and LLDPE were mixed 
in the dual-motion 3D high-speed mixer (JHN-15; Zhengzhou Jintai Metal Material Co., Ltd., Zhengzhou, China) at a speed of $15 \mathrm{r} / \mathrm{min}$ for $10 \mathrm{~min}$ (Fig. 1B). The mixtures were processed with the mini-twin-screw extruder (WLG10G, Shanghai Xinshuo Precision Machinery Co., Ltd., Shanghai, China) at a temperature of $180{ }^{\circ} \mathrm{C}$ and an extrusion speed of $60 \mathrm{r} / \mathrm{min}$ (Fig. 1C). Afterwards, the molten mixture was extruded into the barrel and then put into the micro injection molding machine (WZS10D, Shanghai Xinshuo Precision Machinery Co., Ltd., Shanghai, China) for injection molding (Fig. 1D). The barrel temperature was set at $180{ }^{\circ} \mathrm{C}$, the material tube temperature was $45^{\circ} \mathrm{C}$, and the holding time was 5 s. The obtained composites were abbreviated as CS-PE-SS, where $x$ represented the contents of SS in composites.

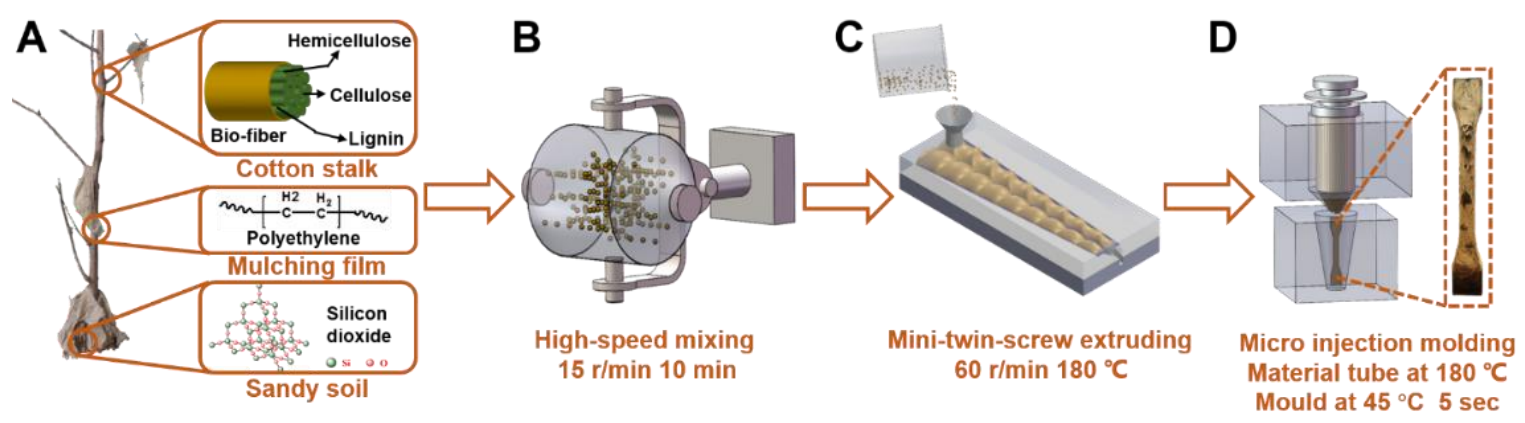

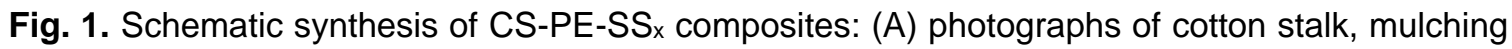
film, and sandy soil (the brown frame emphasizes the main components of cotton stalks, polyethylene, and sandy soil); (B) High-speed mixing; (C) Mini-twin-screw extruding; (D) Micro injection molding and the photograph of CS-PE-SS $x$ composite samples

Table 1. Contents of Different Ingredients in the Formula (wt\%)

\begin{tabular}{|c|c|c|c|c|c|c|c|}
\hline No. & 1 & 2 & 3 & 4 & 5 & 6 & 7 \\
\hline Sandy soil & 0 & 5 & 10 & 15 & 20 & 30 & 40 \\
\hline Cotton stalk & 70 & 65 & 60 & 55 & 50 & 40 & 30 \\
\hline HDPE & 15 & 15 & 15 & 15 & 15 & 15 & 15 \\
\hline LLDPE & 15 & 15 & 15 & 15 & 15 & 15 & 15 \\
\hline
\end{tabular}

\section{Characterization}

Fourier transform infrared (FT-IR) analysis was performed on a Nicolet 5700 FTIR spectrometer (Thermo Fisher Scientific, Waltham, MA, USA) using the KBr pellet method at wavenumber range 400 to $4000 \mathrm{~cm}^{-1}$. The samples were crushed into powders and washed with ethanol three times and dried at $60{ }^{\circ} \mathrm{C}$ for $24 \mathrm{~h}$. The specimens for FT-IR measurement were prepared by grinding the sample solid with $\mathrm{KBr}$ together and then compressed into thin pellets.

X-ray diffraction (XRD) analysis was performed on a Bruker AXS D8 advance polycrystalline X-ray diffractometer (BRUKER AXS GMBH, Karlsruhe, Germany) using $\mathrm{CuK} \alpha$ radiation. The operating voltage was $40 \mathrm{KV}$, the operating current was $50 \mathrm{~mA}$, the sweep range was $5^{\circ}$ to $60^{\circ}$, and the scanning speed was $5^{\circ} / \mathrm{min}$. The samples were crushed, washed with ethanol three times, and dried at $60^{\circ} \mathrm{C}$ for $24 \mathrm{~h}$ before XRD study.

Field emission scanning electron microscopy (FE-SEM, FEI Sirion 200; Thermo Fisher Scientific, Waltham, MA, USA) was used to characterize the surface microstructure of samples. The scanning voltage was set as $10 \mathrm{kV}$. Energy-dispersive X-ray spectroscopy mapping of broken samples was performed to verify the presence and distribution of SS in

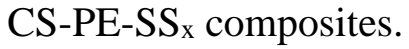


The thermal stabilities of the samples were evaluated using a synchronous thermal analyzer (STA 449, NETZSCH Scientific Instruments Trading Ltd., Selb, Germany). The experiments were conducted in nitrogen atmosphere $(20 \mathrm{~mL} / \mathrm{min})$ with the heating process from $30{ }^{\circ} \mathrm{C}$ to $1100{ }^{\circ} \mathrm{C}$ under a $10{ }^{\circ} \mathrm{C} / \mathrm{min}$ heating rate.

\section{Mechanical properties}

The tensile and flexural properties of the samples were tested with an electronic universal testing machine (WDW1020; Changchun Kexin Co., Ltd., Changchun, China). The samples were cut into dimensions of $80 \times 10 \times 4 \mathrm{~mm}^{3}$ for flexural properties testing, with a $64 \mathrm{~mm}$ bending span and a $5 \mathrm{~mm} / \mathrm{min}$ loading speed. Samples with dimensions of $150 \times 10 \times 4 \mathrm{~mm}^{3}$ were used for tensile properties tests with a $10 \mathrm{~mm} / \mathrm{min}$ stretching speed. The impact performance of the samples $\left(80 \times 10 \times 4 \mathrm{~mm}^{3}\right)$ was tested using a pendulum electronic impact tester (JB-300b; Jinan Hengsi Shengda Instrument Co., Ltd., Jinan, China) under an impact energy of $1 \mathrm{~J}$. All the mechanical properties tests were processed for more than five replicates and averaged for each test.

\section{Flame-retarded properties}

The flame-retardant properties of samples were studied by evaluating their combustion processes. Typically, on one hand, the CS-PE-SS samples $\left(20 \times 10 \times 4 \mathrm{~mm}^{3}\right)$ with different SS contents were ignited by flame envelope for $10 \mathrm{~s}$, and their burning status

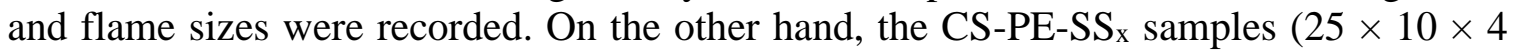
$\mathrm{mm}^{3}$ ) with different SS contents were ignited and kept burning in the air, and their flame out time and burning extents were recorded. An intelligent oxygen index analyzer (ZR-01; Qingdao Shan Fang Instrument Co., Ltd., Qingdao, China) was used to measure the LOI values of CS-PE-SS ${ }_{x}$ composites. The dimensions of samples were $80 \times 10 \times 4 \mathrm{~mm}^{3}$ and the mixed gas flow rate was $40 \pm 2 \mathrm{~mm} / \mathrm{s}$. The LOI values and corresponding estimated standard deviation were calculated according to Eq. 1 ,

$$
O I=C_{f}+k d
$$

where $O I$ represents the limiting oxygen index (vol\%), $C_{f}$ is the last oxygen concentration value (vol\%) of each group of measurements, $d$ represents the difference of the oxygen concentration of each measurement (vol\%), and $k$ is obtained by comparing the last six measurements to find the standard. The value of $d$ can be optimized according to Eqs. 2 and 3 ,

$$
\begin{aligned}
& \hat{\sigma}=\left[\frac{\sum_{i=1}^{n}\left(c_{i}-O I\right)^{2}}{n-1}\right]^{1 / 2} \\
& \frac{2 \hat{\sigma}}{3}<d<1.5 \hat{\sigma}
\end{aligned}
$$

where $\sigma$ represents the standard deviation, $c_{i}$ is the oxygen concentration (vol\%) obtained from the last six measurements of each group, and $n$ is the number of measurements of the oxygen concentration. If $d<(2 \sigma) / 3$, then increase the value of $d$ and repeat the experiment until the condition is met. If $d>1.5 \sigma$, then decrease the value of $d$ and repeat the experiment. 


\section{RESULTS AND DISCUSSION}

\section{FT-IR}

The FT-IR analysis was carried out on SS, LLDPE, CS, and CS-PE-SS $\mathrm{x}_{\mathrm{x}}$ with different SS contents (Fig. 2). For cotton stalk, the bands at $3419 \mathrm{~cm}^{-1}, 2918 \mathrm{~cm}^{-1}$ and 2850 $\mathrm{cm}^{-1}, 1743 \mathrm{~cm}^{-1}, 1633 \mathrm{~cm}^{-1}, 1510 \mathrm{~cm}^{-1}$ and $1455 \mathrm{~cm}^{-1}, 1426 \mathrm{~cm}^{-1}$ and $1375 \mathrm{~cm}^{-1}$, were attributed to the hydrogen bonded $\mathrm{O}-\mathrm{H}$ stretching vibration, $\mathrm{C}-\mathrm{H}$ stretching vibration from $-\mathrm{CH}$ and $-\mathrm{CH}_{2}$ in cellulose and hemicellulose components, $\mathrm{C}=\mathrm{O}$ valance vibration of hemicellulose acetyl group or ester linkage of carboxylic group of feruli and $p$-coumeric acid in lignin, the vibration of $\mathrm{C}=\mathrm{O}$ stretch of conjugated $\mathrm{p}$-substituted aryl ketones, the $\mathrm{C}=\mathrm{C}$ - stretch of the aromatic rings of lignin, and $-\mathrm{CH},-\mathrm{CH}_{2}$ vibrations and aromatic ring modes, respectively (Fig. 2A) (Rahbar Shamskar et al. 2016). However, the characteristic peak at $1743 \mathrm{~cm}^{-1}$ and $1633 \mathrm{~cm}^{-1}$ exhibited blue shifts to $1735 \mathrm{~cm}^{-1}$ and $1624 \mathrm{~cm}^{-1}$ of CSPE-SS 40 , indicating the changes of their chemical environment, which was triggered by the possible interactions between components in CS-PE-SS 40 (Fig. 2B). The main component of sandy soil was silicon dioxide. The polar groups on the surface of silicon dioxide may contribute some interacting forces with biomass, resulting in the shift of the characteristic peaks in the FT-IR spectrum (Boehm 1966). Thus, the interaction between CS and SS indicated promising combination among components, mechanical properties, and functionalities.
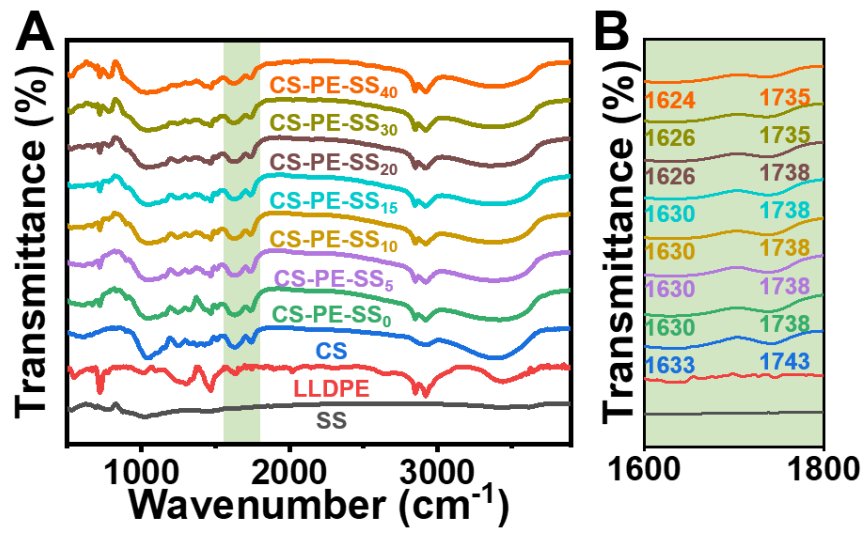

Fig. 2. (A) The FT-IR spectra of CS, SS, LLDPE, and CS-PE-SS ${ }_{x}$ composites with different SS contents; (B) The amplified FT-IR spectra at wavenumber 1600 to $1800 \mathrm{~cm}^{-1}$, emphasizing the blue shift of wavenumber

\section{XRD}

The XRD patterns of CS, HDPE, SS, and CS-PE-SS40 are shown in Fig. 3. The CS showed two regions with peak values of approximately $16.9^{\circ}$ and $22.1^{\circ}$, demonstrated an amorphous state and cellulose I, respectively (Zhou et al. 2020). Two main diffraction peaks of the HDPE could be observed at $21.6^{\circ}$ and $24^{\circ}$, which corresponded to (110) and (200) crystal planes (Zhang et al. 2019). The sandy soil displayed two strong diffraction peaks at $20.9^{\circ}$ and $26.7^{\circ}$, which were assigned to the (100) and (101) crystal planes (Vijay et al. 2019). Similarly, CS-PE-SS 40 composites exhibited the characteristic peaks of HDPE, SS, and CS, implying that the crystal structures of each component were not changed during the preparation procedure. The retainment of intrinsic properties of each component

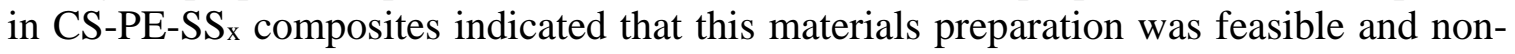
destructive, which was promising in further applications such as flame retard. 


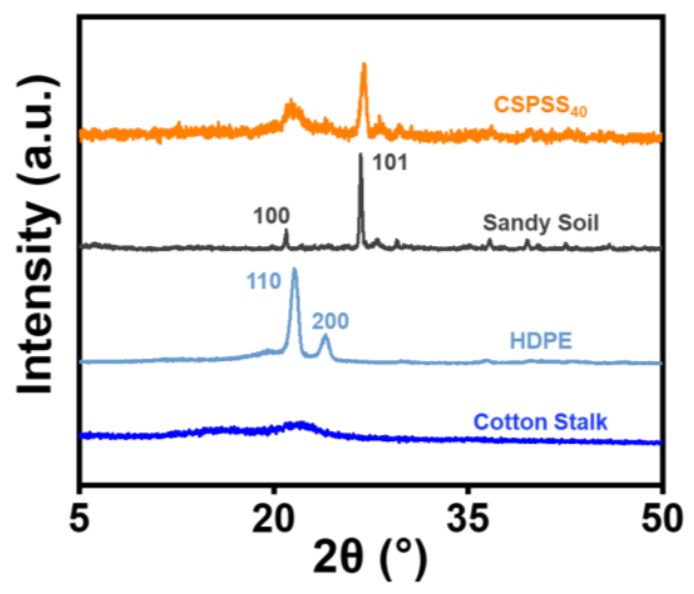

Fig. 3. XRD curves of HDPE, sandy soil, cotton stalk, and CS-PE-SS 40

\section{SEM}

Figure 4A through $4 \mathrm{H}$ showed the cross-section SEM images of CS-PE-SS0-40. Composites without SS exhibited that cotton stalk particles that were well combined with polyethylene matrix (Fig. 4A).

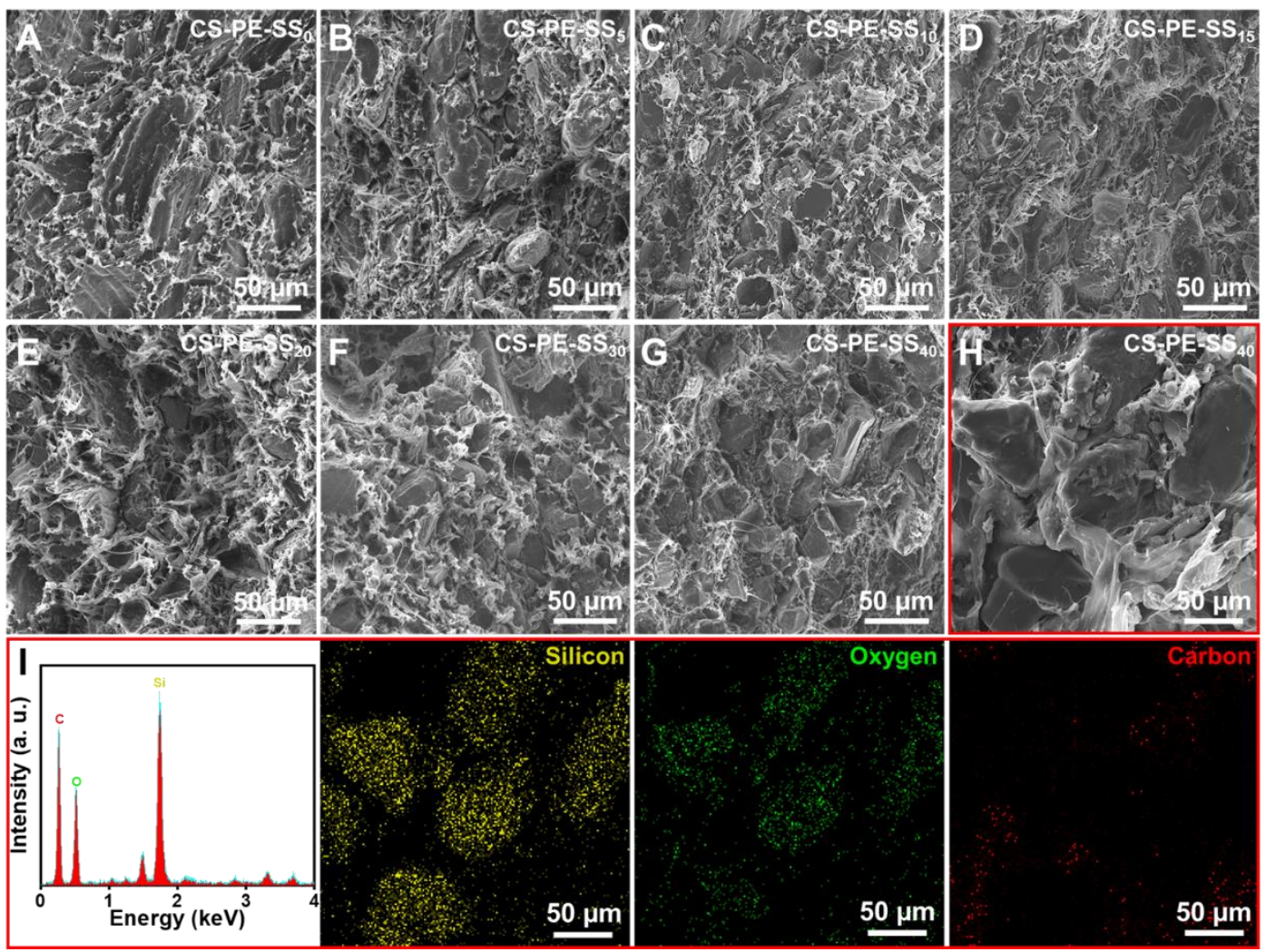

Fig. 4. Scanning electron micrographs of composites with different sandy soil contents (A through G); SEM image of sandy soil $40 \mathrm{wt} \%(\mathrm{H})$, EDS and mapping of silicon, oxygen, and carbon (I)

After adding SS, inorganic particles with diameters ranging from $10 \mu \mathrm{m}$ to $110 \mu \mathrm{m}$ were observed. The distribution of SS in polyethylene matrix became dense and uniform 
as their contents increased, indicating favorable adhesion of polyethylene on the surfaces of SS (Fig. 4B through 4G). In the amplified SEM image of CS-PE-SS40 composites, melt polymer matrix as fluid at high temperature tightly attached onto the surfaces of SS after cooling and showed no obvious cracks (Fig. 4H) (Essabir et al. 2017; Spoerk et al. 2017). The corresponding energy-dispersive X-ray spectrum and mapping further implied the presence and uniform distribution of SS in CS-PE-SS 40 composites (Fig. 4I). The favorable combination in the interfaces and potential interactions between components were critical for the performance of functional composites. Thus, the well dispersion of SS in polymer matrix combined with the tight interface adhesion and interactions between SS and CS particles exhibited promising potential in the development of mechanical properties and thermal stabilities of CS-PE-SS40 composites.

\section{Mechanical Properties of CS-PE-SS $\mathbf{x}$}

To study the impact of SS on the mechanical properties of CS-PE-SS $\mathrm{x}$ composites, the flexural strength, tensile strength, and impact strength of CS-PE-SS 0, CS-PE-SS $10, \mathrm{CS}-$ PE-SS 20, CS-PE-SS 30 , and CS-PE-SS 40 composites were tested (Fig. 5). The mechanical strength, such as flexural strength, tensile strength, and impact strength, increased with more SS addition and reached values of $29.0 \mathrm{MPa}, 15.8 \mathrm{MPa}$, and $3.17 \mathrm{~kJ} / \mathrm{m}^{2}$ for CS-PE$\mathrm{SS}_{40}$ composites, respectively (Figs. 5A through 5C). The improvement of mechanical properties of composites may be attributed to three reasons. Firstly, SS particles with high stiffness were well distributed in polymer matrix. They transferred stress efficiently and

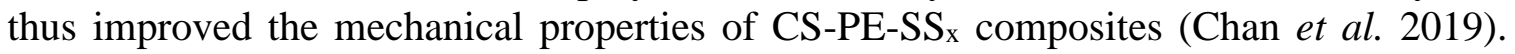
Secondly, the rigid SS particles embedded in polymer matrix may form a concentration of force when external forces were applied, thereby inducing crazing in the interface between SS and polyethylene matrix. Inorganic particles can prevent the development of crazing, and the increase of SS contents inhibits the growth of the number of crazing and improves the strength of the composites (Keskisaari et al. 2016). Lastly, the interacting forces between SS particles and CS powders also endowed composites favorable resistance to external forces and thus improved their mechanical properties. Overall, the composites fabricated with SS, CS, and PE were mechanically strong and suitable for functional woodplastic plate materials.
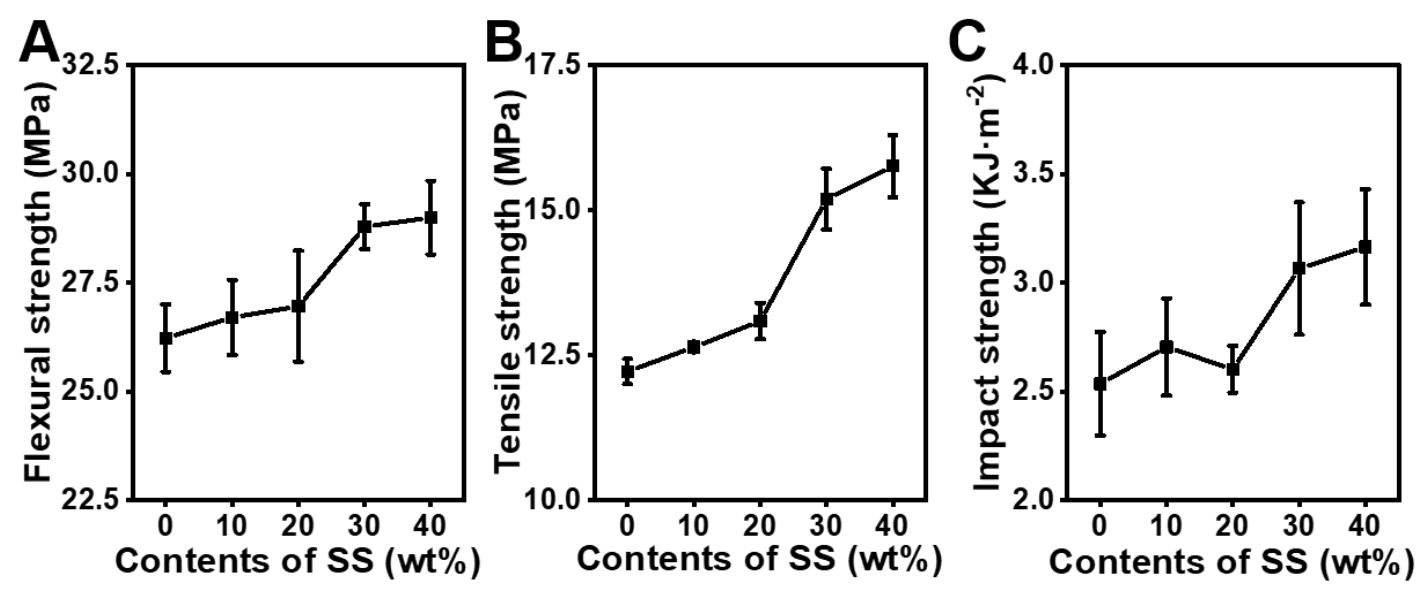

Fig. 5. (A through C) Flexural strength, tensile strength, and impact strength, respectively, of composites with different sandy soil contents 


\section{Thermal Properties of CS-PE-SS $\mathbf{x}$}

The mass loss curves and mass loss derivatives of HDPE, LLDPE, CS, SS, CS-PE$\mathrm{SS}_{0}, \mathrm{CS}-\mathrm{PE}-\mathrm{SS}_{5}, \mathrm{CS}-\mathrm{PE}-\mathrm{SS}_{10}, \mathrm{CS}-\mathrm{PE}-\mathrm{SS}_{15}, \mathrm{CS}-\mathrm{PE}-\mathrm{SS}_{20}, \mathrm{CS}_{2}{\mathrm{PE}-\mathrm{SS}_{30} \text {, and CS-PE-SS}}_{40}$ composites are presented in Fig. 6 to evaluate the effect of SS on the thermal stabilities of CS-PE-SS $\mathrm{x}_{\mathrm{x}}$ composites. Both HDPE and LLDPE presented only one major step of thermal decomposition. The steps around $500{ }^{\circ} \mathrm{C}$ of HDPE and LLDPE were related to the break of carbon-carbon bond of the polymeric chains and formation of volatiles compounds (Moreno and Saron 2017). The main weight loss process of CS was around $350^{\circ} \mathrm{C}$, leading to $55 \%$ of weight loss, which was mainly caused by thermal depolymerization of the hemicellulose, breaking of glycosidic bond of the cellulose, and decomposition of the $\alpha$ cellulose. Lignin in CS also started decomposition at approximately $500{ }^{\circ} \mathrm{C}$ (Guo et al. 2020). However, the thermogravimetric curve of SS exhibited only a weak peak between $630{ }^{\circ} \mathrm{C}$ and $770{ }^{\circ} \mathrm{C}$, which can be attributed to the degradation of $\mathrm{CaCO}_{3}$ into $\mathrm{CaO}$. It was noteworthy that CS-PE-SS $\mathrm{x}_{\mathrm{x}}$ composites showed less mass loss compared with pure CS, HDPE, LDPE, and composites without SS. This may be due to the high thermal stability of SS and strong interacting forces with CS and fine dispersion in polymer matrix, which can prevent the penetration of volatile degradation products from the composites (Subramani et al. 2007; Koohestani et al. 2017). Furthermore, the temperature at $10 \%$ weight loss of CS-PE-SS $\mathrm{x}_{\mathrm{x}}$ composites also increased from $252{ }^{\circ} \mathrm{C}$ of CS to $312{ }^{\circ} \mathrm{C}$ of CSPE-SS 40 . All the results provided good evidence that the thermal stabilities of the composites were enhanced effectively.
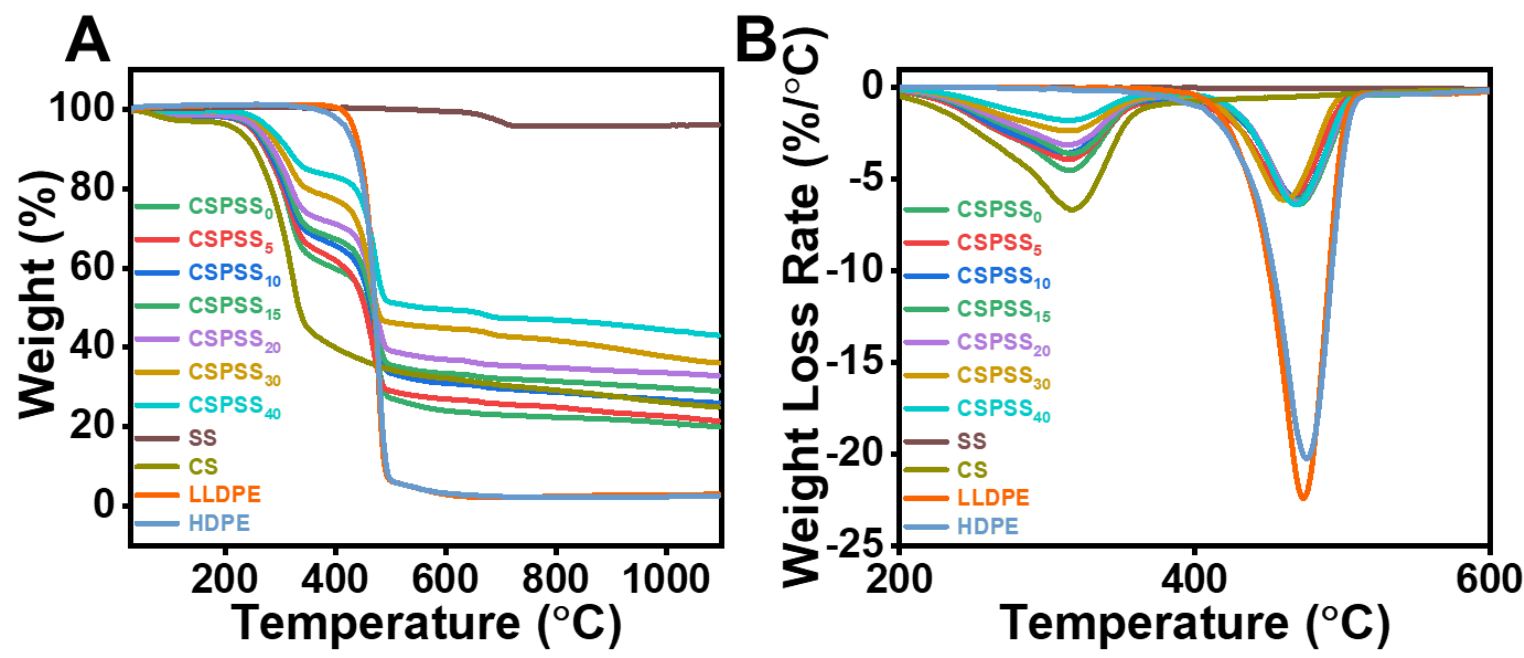

Fig. 6. TG (A) and DTG (B) curves of SS, CS, LLDPE, HDPE, and CS-PE-SS $\times$ composites; the contents of SS were $0 \mathrm{wt} \%, 5 \mathrm{wt} \%, 10 \mathrm{wt} \%, 15 \mathrm{wt} \%, 20 \mathrm{wt} \%, 30 \mathrm{wt} \%$, and $40 \mathrm{wt} \%$, respectively.

\section{Flame Retardant Properties of CS-PE-SS $\mathbf{x}$}

The SS, as an inorganic flame retardant, can effectively weaken the transfer of heat and the volatilization of combustible gas and reduce the contact area between combustible and air, making it difficult for the flame to continue to burn down, and finally improving the flame-retardant properties of the composites (Schirp and Su 2016; Zhang et al. 2017). In Fig. 7A, composites with different SS contents were ignited by flame lighter. It can be observed that when the composite sample only contained cotton stalk and polymer matrix, the flame became very bright after $10 \mathrm{~s}$ of ignition. While the composites with SS addition, it was difficult to ignite. Additionally, with the increase of SS contents, the flame intensity 
decreased obviously and was even unignited for CS-PE-SS40. The flame out time and burning distance were recorded after the tops of the samples were fully ignited (Fig. 7B through 7D). When the contents of SS were $0 \mathrm{wt} \%$, the sample showed sustained combustion until it burned out. However, with the addition of SS, the samples exhibited obvious extinguishment phenomenon and the extinguishment time rapidly decreased (CSPE-SS 40 composites flamed out within $55 \mathrm{~s}$ ). Compared with the composites without SS, the burning distance of the samples contained SS was remarkably shortened and an almost $75 \%$ decrease occurred with only 5 wt $\%$ SS addition.

The LOI value corresponds to the oxygen content required for combustion to occur, and a high limiting oxygen index value means high flame-retarded properties. (Zhou and $\mathrm{Fu} 2020$ ). The LOI values of the composites were shown in Fig. 7E. When the proportion of SS was $0 \mathrm{wt} \%$, the LOI values of the composite was $20.8 \%$. The LOI values of the composites increased gradually with more SS usage. When the proportion of SS reached $40 \mathrm{wt} \%$, the LOI value of the composite reached $24.1 \%$. Many flame retardants, such as aluminum hydrogen phosphonate, triphenyl phosphate, ammonium polyphosphate, and so on, were applied to improve the flame-retardant abilities of wood-plastic composites, and their LOI values were calculated between approximately $18.1 \%$ and $26.6 \%$ (Altun et al.

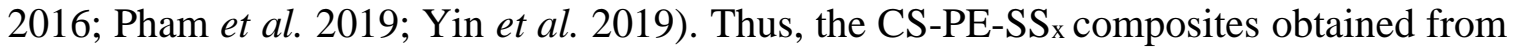
agricultural mulching film wastes were judged to be suitable for flame retard applications.

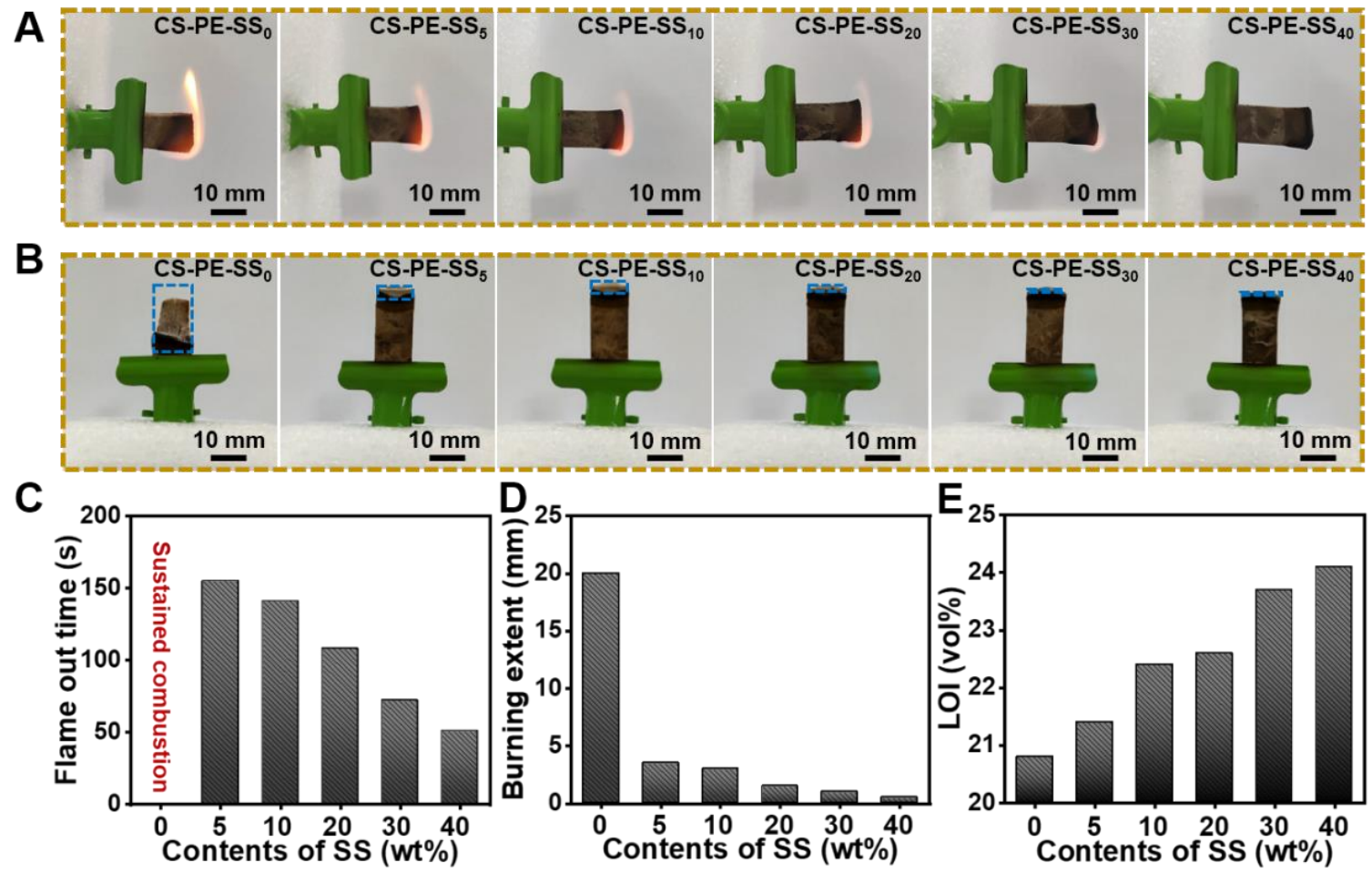

Fig. 7. The $10 \mathrm{~s}$ ignition test of the specimen $(A)$, burning distance tests of the specimen (B), diagram of flame out time (C), diagram of burning extent (D), and LOI values of composites samples (E)

\section{Feasibility Evaluation of the Materials Fabrication}

To evaluate the feasibility of the authors' management on agricultural wastes, soil from Xinjiang, Shandong, and Jiangsu were selected to composite with waste mulching film and cotton stalk. The results showed that all the agricultural wastes used can form 
intact composites with promising properties (Fig. 8A). The flexural strength, tensile strength, and impact strength of the three composites were relatively lower than the commercial wood-plastic composites, but still suitable for applications in plates fields (Hyvärinen et al. 2014). The LOI values of the composites with different soil from three regions were approximately $23.5 \%$, which was higher than that of the sample without soil. These results indicated that the conversion of agricultural wastes into flame retardant materials was feasible, and the waste soil acts as a flame retardant in the composites was of noticeable importance for the authors to develop an efficient and economical strategy to utilize the waste resources.
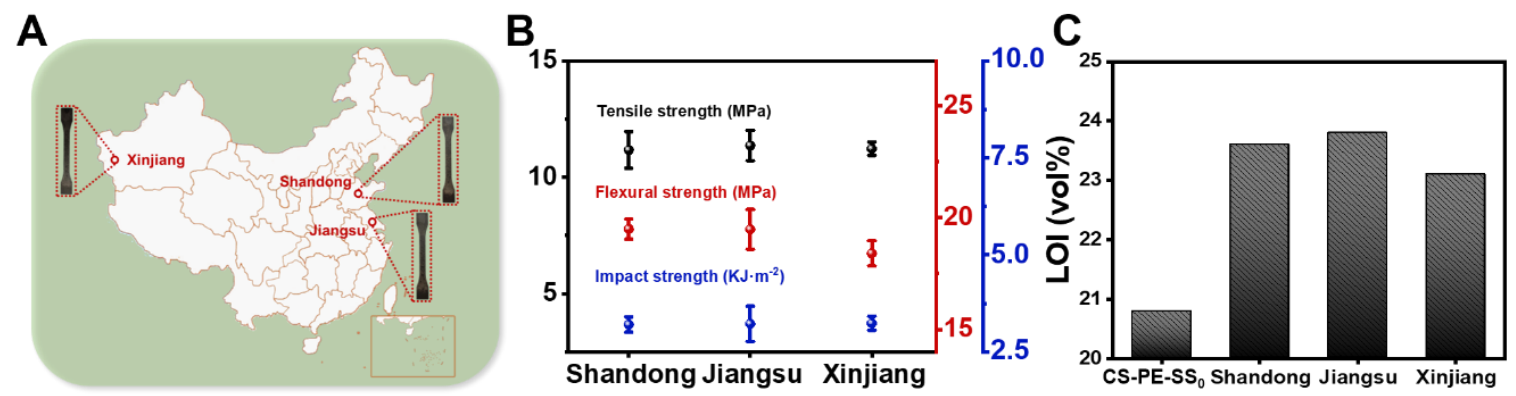

Fig. 8. (A) Soil acquired in different provinces of China and the photographs of corresponding composites; (B) Mechanical properties; and (C) LOI values of the composites fabricated using agricultural mulching film wastes from Shandong, Jiangsu, and Xinjiang province of China

\section{CONCLUSIONS}

1. Simple compounding and injection molding procedures were applied to convert plastic agriculture mulching film wastes into functional flame-retarded composites directly. The added sandy soil particles were uniformly dispersed in the polymer matrix and showed promising interface combination.

2. The resultant composites showed a flexural strength of approximately 29.0 MPa, a tensile strength approximately $15.8 \mathrm{MPa}$, an impact strength of approximately 3.17 $\mathrm{kJ} / \mathrm{m}^{2}$ and improved thermal stabilities.

3. The addition of sandy soil particles endowed materials favorable flame-retarded properties, which can resistant to fire ignition and flame out within $55 \mathrm{~s}$.

\section{ACKNOWLEDGMENTS}

The authors are grateful for the support of the financial support of the National Key Research and Development Program of China (No. 2018YFD1101001); the distinguished expert of Taishan scholars Shandong province project and the higher education superior discipline team training program of Shandong province. 


\section{REFERENCES CITED}

Abdel-Rahman, H. A., Awad, E. H., and Fathy, R. M. (2020). "Effect of modified nano zinc oxide on physico-chemical and antimicrobial properties of gamma-irradiated sawdust/epoxy composites," J. Compos. Mater. 54(3), 331-343. DOI: 10.1177/0021998319863835

Altun, Y., Doğan, M., and Bayraml1, E. (2016). "Flammability and thermal degradation behavior of flame retardant treated wood flour containing intumescent LDPE composites," Eur. J. Wood Wood Prod. 74, 851-856. DOI: 10.1007/s00107-0161042-1

Boehm, H. P. (1966). "Functional groups on the surfaces of solids," Angew. Chem. Int. Ed. Engl. 5(6), 533-544. DOI: 10.1002/anie.196605331

Borah, J. S., and Kim, D. S. (2016). "Recent development in thermoplastic/wood composites and nanocomposites: A review," Korean J. Chem. Eng. 33, 3035-3049. DOI: $10.1007 / \mathrm{s} 11814-016-0183-6$

Briassoulis, D., and Schettini, E. (2003). "Analysis and design of low-density polyethylene greenhouse films," Biosyst. Eng. 84(3), 303-314. DOI: 10.1016/S15375110(02)00241-6

Chan, C. M., Vandi, L., Pratt, S., Halley, P., Richardson, D., Werker, A., and Laycock, B. (2017). "Composites of wood and biodegradable thermoplastics: A review," Polym. Rev. 58(3), 444-494. DOI: 10.1080/15583724.2017.1380039

Chan, J. X., Wong, J. F., Hassan, A., Mohamad, Z., and Othman, N. (2019). "Mechanical properties of wollastonite reinforced thermoplastic composites: A review," Polym. Composite. 41(2), 395-429. DOI: 10.1002/pc.25403

Chen, N., Li, X., Šimůnek, J., Shi, H., Ding, Z., and Zhang, Y. (2020). "The effects of biodegradable and plastic film mulching on nitrogen uptake, distribution, and leaching in a drip-irrigated sandy field," Agric. Ecosyst. Environ. 292, Article ID 106817. DOI: 10.1016/j.agee.2020.106817

de Souza Machado, A. A., Lau, C. W., Kloas, W., Bergmann, J., Bachelier, J. B., Faltin, E., Becker, R., Görlich, A. S., and Rillig, M. C. (2019). "Microplastics can change soil properties and affect plant performance," Environ. Sci. Technol. 53(10), 60446052. DOI: 10.1021/acs.est.9b01339

Essabir, H., Bensalah, M. O., Rodrigue, D., Bouhfid, R., and Qaiss, A. E. K. (2017). “A comparison between bio- and mineral calcium carbonate on the properties of polypropylene composites," Constr. Build. Mater. 134, 549-555. DOI: 10.1016/j.conbuildmat.2016.12.199

Gu, X., Li, Y., and Du, Y. (2017). "Biodegradable film mulching improves soil temperature, moisture and seed yield of winter oilseed rape (Brassica napus L.)," Soil Tillage Res. 171, 42-50. DOI: 10.1016/j.still.2017.04.008

Guo, Y., Wang, L., Wang, H., Chen, Y., Zhu, S., Chen, T., and Luo, P. (2020). "Properties of bamboo flour/high-density polyethylene composites reinforced with ultrahigh molecular weight polyethylene," J. Appl. Polym. Sci. 137(33), Article ID 48971. DOI: 10.1002/app.48971

Guzel, G., Sivrikaya, O., and Deveci, H. (2016). "The use of colemanite and ulexite as novel fillers in epoxy composites: Influences on thermal and physico-mechanical properties," Compos. Part B-Eng. 100, 1-9. DOI: 10.1016/j.compositesb.2016.06.054

Hao, X., Zhou, H., Xie, Y., Xiao, Z., Wang, H., and Wang, Q. (2018). "Mechanical reinforcement and creep resistance of coextruded wood flour/polyethylene 
composites by shell-layer treatment with nano - and micro-SiO 2 particles," Polym. Compos. 40(4), 1576-1584. DOI: 10.1002/pc.24901

Hemphill, D. D. J. (1993). "Agricultural plastics as solid waste: What are the options for disposal?," HortTechnology 3(1), 70-73. DOI: 10.21273/HORTTECH.3.1.70

He, D., Luo, Y., Lu, S., Liu, M., Song, Y., and Lei, L. (2018). "Microplastics in soils: Analytical methods, pollution characteristics and ecological risks," TrAC, Trends Anal. Chem. 109, 163-172. DOI: 10.1016/j.trac.2018.10.006

Hu, Q., Li, X., Gonçalves, J. M., Shi, H., Tian, T., and Chen, N. (2020). "Effects of residual plastic-film mulch on field corn growth and productivity," Sci. Total Environ. 729, Article ID 138901. DOI: 10.1016/j.scitotenv.2020.138901

Hyvärinen, M., Paajanen, J., and Kärki, T. (2014). "Determination and comparison of material properties of commercial wood-plastic composite products," Adv. Mater. Res. 1051, 242-249. DOI: 10.4028/www.scientific.net/AMR.1051.242

Kasirajan, S., and Ngouajio, M. (2012). "Polyethylene and biodegradable mulches for agricultural applications: A review," Agron. Sustainable Dev. 33, 443. DOI: 10.1007/s13593-012-0132-7

Keskisaari, A., Butylina, S., and Kärki, T. (2016). "Use of construction and demolition wastes as mineral fillers in hybrid wood-polymer composites," J. Appl. Polym. Sci. 133(19), Article ID 43412. DOI: 10.1002/app.43412

Koohestani, B., Ganetri, I., and Yilmaz, E. (2017). "Effects of silane modified minerals on mechanical, microstructural, thermal, and rheological properties of wood plastic composites," Compos. Part B- Eng. 111, 103-111. DOI: 10.1016/j.compositesb.2016.12.021

Lambert, S., and Wagner, M. (2017). "Environmental performance of bio-based and biodegradable plastics: The road ahead," Chem. Soc. Rev. 46(22), 6855-6871. DOI: 10.1039/C7CS00149E

Lee, J. G., Cho, S. R., Jeong, S. T., Hwang, H. Y., and Kim, P. J. (2019). “Different response of plastic film mulching on greenhouse gas intensity (GHGI) between chemical and organic fertilization in maize upland soil," Sci. Total Environ. 696, Article ID 133827. DOI: 10.1016/j.scitotenv.2019.133827

Liu, E. K., He, W. Q., and Yan, C. R. (2014). "'White revolution' to 'white pollution'agricultural plastic film mulch in China," Environ. Res. Lett. 9(9), Article ID 091001. DOI: 10.1088/1748-9326/9/9/091001

Liu, L., Zhang, Y., Lv, F., Yang, B., and Meng, X. (2016a). "Effects of red mud on rheological, crystalline, and mechanical properties of red mud/PBAT composites," Polym. Compos. 37(7), 2001-2007. DOI: 10.1002/pc.23378

Liu, R., Chen, Y., and Cao, J. (2016b). "Effects of modifier type on properties of in situ organo-montmorillonite modified wood flour/poly (lactic acid) composites," ACS Appl. Mater. Interfaces. 8(1), 161-168. DOI: 10.1021/acsami.5b07989

Liu, M., Lu, S., Song, Y., Lei, L., Hu, J., Lv, W., Zhou, W., Cao, C., Shi, H., Yang, X., and He, D. (2018). "Microplastic and mesoplastic pollution in farmland soils in suburbs of Shanghai, China," Environ. Pollut. 242(Part A), 855-862. DOI: 10.1016/j.envpol.2018.07.051

Ma, Y., He, H., Huang, B., Jing, H., and Zhao, Z. (2019). "In situ fabrication of wood flour/nano silica hybrid and its application in polypropylene-based wood-plastic composites," Polym. Compos. 41(2), 573-584. DOI: 10.1002/pc.25389

Matykiewicz, D., Barczewski, M., and Michałowski, S. (2019). "Basalt powder as an eco-friendly filler for epoxy composites: Thermal and thermo-mechanical properties 
assessment," Compos. Part B- Eng. 164, 272-279. DOI:

10.1016/j.compositesb.2018.11.073

Mohanty, A. K., Vivekanandhan, S., Pin, J. M., and Misra, M. (2018). "Composites from renewable and sustainable resources: Challenges and innovations," Science 362(6414), 536-542. DOI: 10.1126/science.aat9072

Moreno, D. D. P., and Saron, C. (2017). "Low-density polyethylene waste/recycled wood composites," Compos. Struct. 176, 1152-1157. DOI: 10.1016/j.compstruct.2017.05.076

Mu, B., Wang, H., Hao, X., and Wang, Q. (2018). "Morphology, mechanical properties and dimensional stability of biomass particles/high density polyethylene composites: Effect of species and composition," Polymers 10, Article number 308. DOI: 10.3390/polym 10030308

Ng, E., Huerta Lwanga, E., Eldridge, S. M., Johnston, P., Hu, H., Geissen, V., and Chen, D. (2018). "An overview of microplastic and nanoplastic pollution in agroecosystems," Sci. Total Environ. 627, 1377-1388. DOI: 10.1016/j.scitotenv.2018.01.341

Nkwachukwu, O., Chima, C., Ikenna, A., and Albert, L. (2013). "Focus on potential environmental issues on plastic world towards a sustainable plastic recycling in developing countries," Int. J. Ind. Chem. 4, Article number 34. DOI: 10.1186/22285547-4-34

Pham, L. H., Nguyen, H. D., Kim, J., and Hoang, D. (2019). "Thermal properties and fire retardancy of polypropylene/wood flour composites containing eco-friendly flame retardants," Fibers Polym. 20, 2383-2389. DOI: 10.1007/s12221-019-1179-8

Qi, Y., Yang, X., Pelaez, A. M., Huerta Lwanga, E., Beriot, N., Gertsen, H., Garbeva, P., and Geissen, V. (2018). "Macro- and micro- plastics in soil-plant system: Effects of plastic mulch film residues on wheat (Triticum aestivum) growth," Sci. Total Environ. 645, 1048-1056. DOI: 10.1016/j.scitotenv.2018.07.229

Rahbar Shamskar, K., Heidari, H., and Rashidi, A. (2016). "Preparation and evaluation of nanocrystalline cellulose aerogels from raw cotton and cotton stalk," Ind. Crop. Prod. 93, 203-211. DOI: 10.1016/j.indcrop.2016.01.044

Sanchez-Hernandez, J. C., Capowiez, Y., and Ro, K. S. (2020). "Potential use of earthworms to enhance decaying of biodegradable plastics," ACS Sustain. Chem. Eng. 8(11), 4292-4316. DOI: 10.1021/acssuschemeng.9b05450

Schirp, A., and Su, S. (2016). "Effectiveness of pre-treated wood particles and halogenfree flame retardants used in wood-plastic composites," Polym. Degrad. Stabil. 126, 81-92. DOI: 10.1016/j.polymdegradstab.2016.01.016

Sommerhuber, P. F., Welling, J., and Krause, A. (2015). "Substitution potentials of recycled HDPE and wood particles from post-consumer packaging waste in woodplastic composites," Waste. Manage. 46, 76-85. DOI: 10.1016/j.wasman.2015.09.011

Spoerk, M., Sapkota, J., Weingrill, G., Fischinger, T., Arbeiter, F., and Holzer, C. (2017). "Shrinkage and warpage optimization of expanded-perlite-filled polypropylene composites in extrusion-based additive manufacturing," Macromol. Mater. Eng. 302(10), Article ID 1700143. DOI: 10.1002/mame.201700143

Steinmetz, Z., Wollmann, C., Schaefer, M., Buchmann, C., David, J., Tröger, J., Muñoza, K., Frörd, O., and Schaumannet, G. E. (2016). "Plastic mulching in agriculture. Trading short-term agronomic benefits for long-term soil degradation?," Sci. Total Environ. 550, 690-705. DOI: 10.1016/j.scitotenv.2016.01.153 
Subramani, S., Lee, J. Y., Kim, J. H., and Cheong, I. W. (2007). "Crosslinked aqueous dispersion of silylated poly (urethane-urea)/clay nanocomposites," Compos. Sci. Technol. 67(7-8), 1561-1573. DOI: 10.1016/j.compscitech.2006.07.011

Tong, J., Royan, N. R., Ng, Y. C., Ab Ghani, M. H., and Ahmad, S. (2014). "Study of the mechanical and morphology properties of recycled HDPE composite using rice husk filler," Adv. Mater. Sci. Eng. 2014, 1-06. DOI: 10.3390/polym10030308

Vigneshwaran, S., Uthayakumar, M., and Arumugaprabu, V. (2019). "Development and sustainability of industrial waste-based red mud hybrid composites," J. Clean. Prod. 230, 862-868. DOI: 10.1016/j.jclepro.2019.05.131

Vijay, R., Lenin Singaravelu, D., Vinod, A., Sanjay, M. R., Siengchin, S., Jawaid, M., Khane, A., and Parameswaranpillai, J. (2019). "Characterization of raw and alkali treated new natural cellulosic fibers from Tridax procumbens," Int. J. Biol. Macromol. 125, 99-108. DOI: 10.1016/j.ijbiomac.2018.12.056

Vox, G., Loisi, R. V., Blanco, I., Mugnozza, G. S., and Schettini, E. (2016). "Mapping of agriculture plastic waste," Agric. Agric. Sci. Procedia 8, 583-591. DOI: 10.1016/j.aaspro.2016.02.080

Wang, C., Cai, Z., Wang, T., and Chen, K. (2020). "Preparation and thermal properties of shape-stabilized 1, 8-octanediol $/ \mathrm{SiO}_{2}$ composites via sol gel methods," Mater. Chem. Phys. 250, Article ID 123041. DOI: 10.1016/j.matchemphys.2020.123041

Yang, J., Ching, Y., and Chuah, C. (2019). "Applications of lignocellulosic fibers and lignin in bioplastics: A review," Polymers 11(5), Article number 751. DOI: 10.3390/polym11050751

Yin, H., Sypaseuth, F. D., Schubert, M., Schoch, R., Bastian, M., and Schartel, B. (2019). "Routes to halogen-free flame-retardant polypropylene wood plastic composites," Polym. Adv. Technol. 30(1), 187-202. DOI: 10.1002/pat.4458

Zhang, Q., Cai, H., Yang, K., and Yi, W. (2017). "Effect of biochar on mechanical and flame retardant properties of wood - Plastic composites," Results Phys. 7, 2391-2395. DOI: 10.1016/j.rinp.2017.04.025

Zhang, Q., Khan, M. U., Lin, X., Cai, H., and Lei, H. (2019). “Temperature varied biochar as a reinforcing filler for high-density polyethylene composites," Compos. Part B-Eng. 175, Article ID 107151. DOI: 10.1016/j.compositesb.2019.107151

Zheng, A., Jiang, L., Zhao, Z., Huang, Z., Zhao, K., Wei, G., Wang, X., He, F., and Li, H. (2015). "Impact of torrefaction on the chemical structure and catalytic fast pyrolysis behavior of hemicellulose, lignin, and cellulose," Energ. Fuels 29(12), 8027-8034. DOI: 10.1021/acs.energyfuels.5b01765

Zhou, L., and Fu, Y. (2020). "Flame-retardant wood composites based on immobilizing with chitosan/sodium phytate/nano- $\mathrm{TiO}_{2}-\mathrm{ZnO}$ coatings via layer-by-layer selfassembly," Coatings 10(3), Article number 296. DOI: 10.3390/coatings 10030296

Zhou, B., Wang, L., Ma, G., Zhao, X., and Zhao, X. (2020). "Preparation and properties of bio-geopolymer composites with waste cotton stalk materials," J. Clean. Prod. 245, Article ID 118842. DOI: 10.1016/j.jclepro.2019.118842

Zhu, T. T., Zhou, C. H., Kabwe, F. B., Wu, Q. Q., Li, C. S., and Zhang, J. R. (2019). "Exfoliation of montmorillonite and related properties of clay/polymer nanocomposites," Appl. Clay Sci. 169, 48-66. DOI: 10.1016/j.clay.2018.12.006

Article submitted: November 10, 2020; Peer review completed: February 6, 2021; Revised version received and accepted; February 21, 2021; Published: February 26, 2021. DOI: $10.15376 /$ biores.16.2.2838-2852 